\title{
Peningkatan Kompetensi Dalam Menunjang Kinerja Karyawan Pada PT Batang Bumi Mandiri
}

\author{
Dekky SI Efendi, Sonny Hersonna, DJ Suyaman \\ Universitas Singaperbangsa Karawang \\ jajang@fe.unsika.ac.id
}

\begin{abstract}
ABSTRAK
Kompetensi dalam sebuah organisasi atau perusahaan merupakan hal yang penting dalam menunjang kinerja yang dihasilkan oleh karyawan. Pihak manajemen tentu saja akan melakukan upaya dalam peningkatan komptensi karyawannya dengan harapan kinerja yang dimiliki karyawan akan membuat pekerjaan mereka dapat terselesaikan dan output yang dihasilkan berkualitas. Menyadari pentingnya kompetensi terhadap kinerja maka penulis turut membantu dengan meneliti variabel tesebut. Dalam penelitian ini peneliti mengumpulkan data dengan membagikan kepada selutuh karyawan pada PT Batang Bumi Mandiri dengan total 25, yang mana seluruh populasi juga akan dijadikan sampel karena digunakan metode pengambilan sampel dengan teknik sampel jenuh. Dalam pengolahan data ini digunakan alat bantu pengolahan data statistic berupa SPSS versi 26 untuk membantu penulis dalam mengolah data penelitian. Hasil penelitian yang diperoleh adalah kompetensi berpengaruh terhadap kinerja. Variabel kompetensi juga memiliki koefisien determinasi sebesar 16,5\% untuk mempengaruhi kinerja, sedangkan sisanya sebesar $83,5 \%$ dipengaruhi oleh variabel lain yang tidak diteliti dalam penelitian ini.
\end{abstract}

Kata Kunci: Kompetensi, Konerja Karyawan

\begin{abstract}
Competence in an organization or company is important in supporting the performance produced by employees. The management of course will make efforts to increase the competence of its employees with the hope that the performance of the employees will make their work complete and the output produced is of high quality. Recognizing the importance of competence on performance, the authors helped by examining these variables. In this study the researchers collected data by distributing it to all employees at PT Batang Bumi Mandiri with a total of 25, of which the entire population will also be sampled because the sampling method used is the saturated sample technique. In processing this data used statistical data processing tools in the form of SPSS version 26 to assist the author in processing research data. The result of the research is that competence has an effect on performance. The competency variable also has a coefficient of determination of $16.5 \%$ to affect performance, while the remaining $83.5 \%$ is influenced by other variables not examined in this study.
\end{abstract}

Keyword: competence, performance

\section{PENDAHULUAN}

Setiap tahunnya tentu terjadi pertumbuhan penduduk yang diikuti oleh pendapatan dosmestik bruto yang meningkat. Sebagai akibatnya tentu saja kebutuhan minyak nabati dan lemak juga meningkat karena ini termasuk kedalam kebutuhan pokok manusia Menyikapi hal ini menurut Pahan, (2008: 17) pemerintah telah mendorong peningkatan pengusahaan kebun kelapa sawit karena output yang dihasilkan merupakan bahan baku pembuatan minyak makan. Salah satu perusahaan yang bergerak dibidang industri kelapa sawit adalah PT Batang Bumi Mandiri, yang juga menjadi objek penelitian ini.

Terdapat pendapat yang pada kenyataannya sulit disangkal mengenai manusia merupakan unsur terpenting dalam setiap organisasi, termasuk juga PT Batang Bumi Mandiri. Sumber daya manusia merupakan penggerak dalam sebuah organisasi untuk mencapai tujuan organisasi tersebut, dalam hal ini tentu saja PT Batang Bumi Mandiri menginginkan produk yang dihasilkan berkualitas agar mampu 
meraih laba yang sesuai dengan perencanaan. Secara tidak langsung ini membuat PT Batang Bumi Mandiri membutuhkan karyawan yang memiliki kinerja yang baik, yang mana dalam penelitian ini akan ditinjau dari kompetensi karwayan. Jika dilihat dari data absensi bulanan karyawan, masih terdapat karyawan yang melakukan absensi tanpa keterangan bahkan terlambat.

Tabel 1. Absensi Karyawan

\begin{tabular}{|c|c|c|c|c|}
\hline \multirow[b]{2}{*}{ Bulan } & \multirow{2}{*}{$\begin{array}{c}\text { Total } \\
\text { Karyawan }\end{array}$} & \multicolumn{2}{|c|}{ Tidak Hadir } & \multirow[b]{2}{*}{ Telat } \\
\hline & & Sakit & $\begin{array}{c}\text { Tanpa } \\
\text { Keterangan }\end{array}$ & \\
\hline Juli & 25 & 8 & 4 & 24 \\
\hline Agustus & 25 & 3 & 3 & 17 \\
\hline September & 25 & 4 & 5 & 13 \\
\hline Oktober & 25 & 3 & 5 & 21 \\
\hline November & 25 & 4 & 2 & 21 \\
\hline Desember & 25 & 6 & 9 & 15 \\
\hline
\end{tabular}

Sumber : Personalia PT Batang Bumi Mandiri periode Juli-Desember

Dari data yang ada dapat di interpretasikan bahwa kinerja dari PT Batang Bumi Mandiri belum maksimal dan perlu adanya peningkatan kualitas sumber daya manusia. Kinerja dari karyawan tentu saja perlu menjadi sorotan dari pihak manajemen yang mengharapkan adanya kinerja yang efektif dalam menyelesaikan tugas masing-masing karyawan. Wibowo (2012 : 324) mengungkapkan bahwa kompetensi merupakan kemampuan dalam menyelesaikan tugas dengan keterampilan dan pengetahuan. Dengan dibekali kompetensi terhadap karwayan akan menunjukkan profesionalisme dalam menyelesaikan tugas-tugasnya. Hasil wawancara dengan bagian personalia mendapati informasi bahwa perusahaan telah melakukan upaya dalam peningkatan kompetensi dengan mengadakan pendidikan dan pelatihan atau diklat untuk karyawankaryawannya. Maka dalam membantu upaya tersebut, penulis melakukan penelitian ini yang berjudul "Pengaruh Kompetensi Terhadap Kinerja Karyawan PT Batang Bumi Mandiri”,

\section{KAJIAN PUSTAKA}

\section{Kompetensi}

Menurut Wibowo (2014: 271), kompetensi merupakan kemampuan untuk melakukan atau melaksanakan pekerjaan atau tugas yang berdasarkan pengetahuan dan keterampilan. Sikap kerja yang diharuskan pada pekerjaan tersebut sangat mendukung terjadinya kompetensi. Perpaduan antara keterampilan, kreativitas, pengetahuan, dan sikap positif saat bekerja akan menghasilkan kinerja dari karyawan. Pemahaman terhadap visi, misi, tujuan, dan nilai perusahaan sangat dibutuhkan untuk mewujudkan kompetensi. Terdapat dua jenis kompetensi yang terkait dengan kemampuan karyawan, yakni kompetensi manajerial dan kompetensi fungsional. Kompetensi manajerial adalah kompetensi terhadap kemampuan untuk menjalankan fungsi manajemen perusahaan. Sedangkan kompetensi fungsional adalah kompetensi terhadap kemampuan untuk menjalankan fungsi teknis tertentu sesuai bidang pekerjaan.

\section{Faktor yang mempengaruhi Kompetensi}

Terdapat beberapa faktor yang mempengaruhi kompetensi Wibowo (2014: 283), antara lain

1. Keyakinan dan nilai-nilai

Merupakan faktor keyakinan tentang dirinya sendiri dan orang lain yang dapat mempengaruhi perilaku.

\section{Keterampilan}

Pekerja membutuhkan pengembangan keterampilan, hal ini terkait dengan kompetensi untuk bisa memberikan nilai lebih pada organisasi dan individu.

\section{Pengalaman}

Keahlian dari pekerja timbul berdasarkan pengalaman yang telah dilakukan.

\section{Karakteristik Kepribadian}

Kepribadian berpengaruh terhadap kompetensi seperti dalam aktivitas penyelesaian konflik, kepedulian organisasi, kerjasama tim, dan komunikasi.

\section{Motivasi}

Motivasi merupakan dorongan yang mempengaruhi individu dalam pekerjaannya.

6. Isu Emosional

Isu emosional menjadi hambatan dalam penguasaan kompetensi.

\section{Kemampuan Intelektual}

Kemampuan intelektual bergantung kepada pemikiran kognitif individu yakni analitikal dan konseptual.

\section{Budaya Organisasi}

Budaya organisasi berpengaruh terhadap kompetensi dalam praktik aktivitas di organisasi mulai dari awal karyawan bergabung, hingga keseluruhan proses 
pengembangan, pengambilan keputusan, pemahaman terhadap nilai, dan lain sebagainya.

\section{Kinerja}

Menurut Wibowo (2014: 2) kinerja merupakan serangkaian nilai perilaku karyawan yang berdampak secara positif dan negative kepada pencapaian tujuan organisasi. Sedangkan menurut Rifai, (2009: 10) kinerja merupakan proses untuk mencipatakan pemahaman menyeluruh antara karyawan dengan atasannya mengenai tujuan organisasi dan cara untuk mencapai tujuan tersebut.

\section{Faktor yang Mempengaruhi Kinerja}

Menurut Wibowo (2014: 84) terdapat faktor yang mempengaruhi kinerja, antara lain.

1. Personal factor

Personal factor dilihat berdasarkan tingkat keterampilan dan kompetensi yang dimiliki serta komtimen dari individu, serta motivasinya.

2. Leadership factor

Leadership factor dilihat dari kualitas dorongan, dukungan, dan bimbingan yang dilakukan oleh atasan.

3. Team factor

Team factor dilihat dari kualitas dorongan dan dukungan yang dilakukan oleh rekan kerja.

4. System factor

System factor dilihat dari fasilitas pendukung dan sistem kerja yang diberikan oleh organisasi.

5. Contextual/Situational Factor

Contextual/Situational factor dilihat berdasarkan tingkat tekanan dan beban pekerjaan pada perubahan lingkungan internal dan eksternal.

\section{Hubungan Kompetensi dan Kinerja}

Kompetensi menjadi faktor yang menentukan kinerja bagi karyawan. Untuk bisa membangun pengelolaan organisasi yang baik dan efektivitas perilaku dari manajemen. Perlu dilakukan identifikasi dari kebutuhan kompetensi organisasi dan keseluruhan bidang yang terkait pada organisasi. Menentukan kebutuhan kompetensi dibutuhkan untuk mengetahui tingkat kinerja yang diinginkan organisasi. Selain itu, penentuan kompetensi juga menjadi dasar untuk evaluasi kinerja dari organisasi dan karyawan. Kompetensi juga dapat digunakan untuk menetapkan posisi kerja karyawan. Karyawan yang akan menempati posisi tertentu harus memiliki kompetensi yang sesuai. Salah satu cara untuk mengetahui, yakni dengan dilakukan evaluasi kompetensi sesuai pengukuran kinerja. Hal ini akan membuat sistem pengelolaan sumber daya manusia (SDM) pada organisasi menjadi lebih terarah dan karyawan bisa terus melakukan pengembangan keterampilan dan pengetahuan untuk bisa meningkatkan kompetensi, dan menghasilkan dampak kinerja yang positif pada organisasi. Oleh karena itu, kompetensi dan kinerja memiliki hubungan yang sangat kuat. Dengan begitu dalam penelitian ini diajukan hipotesis sebagai berikut :

$\mathrm{H}_{0}$ : Kompetensi tidak berpengaruh terhadap kinerja

$\mathrm{H}_{1}$ : Kompetensi berpengaruh terhadap kinerja

\section{METODE PENELITIAN}

Populasi dalam penelitian ini adalah seluruh karyawan pada PT Batang Bumi Mandiri yang berjumlah 25 karyawan. Pada pengambilan sampel dalam penelitian ini menggunakan metode sampel jenuh karena berhubung total populasi kurang dari 30. (Sugiyono, 2019) mengatakan bahwa metode sampel jenuh dapat digunakan saat populasi kurang dari 30 atau penulis ingin mengenerelasi penelitiannya dengan maksud untuk minimalkan kesalahan. Dalam pengumpulan data digunakan data primer dan sekunder. Data primer ini digunakan karena penelitian menggunakan kuisioner yang disebar kepada sampel penelitian sebagai responden dengan opsi jawaban menggunakan skala likert 1 sampai 5 yang berarti sangat tidak setuju untuk poin 1 sampai sangat setuju untuk poin 5 dan juga dilakukan wawancara langsung kepada pihak personalia untuk mengetahui permasalahan dalam perusahaan. Untuk data sekundernya dalam penelitian ini juga dilakukan untuk mendukung data primer dengan literatur kepustakaan sebagai landasan teori dalam penelitian ini. Untuk analisis data akan digunakan alat bantu statistic berupa aplikasi spss versi 26 dengan pengujian kualitas data yang terdiri dari uji validitas dan reliabilitas, lalu dilakukan uji asumsi klasik, uji regresi linier sederhana dan uji hipotesis.

\section{HASIL PENELITIAN}

Uji Statistik deskriptif

Tabel 2. Uji Statistik deskriptif

\begin{tabular}{lr|r|r|r|r} 
& & & & & \multicolumn{1}{c}{ Std. } \\
& N & Minimum & Maximum & Mean & Deviation \\
\hline Kompetensi & 25 & 23 & 55 & 37.64 & 7.376 \\
\hline Kinerja & 25 & 29 & 40 & 34.44 & 3.895 \\
\hline Valid N (listwise) & 25 & & & & \\
\hline \multicolumn{2}{c|}{ Sumberiptive Statistics } \\
\hline
\end{tabular}

Sumber : SPSS.26, diolah penulis (2021) 
Berdasarkan pengujian statistic desktiptif dapat diketahui bahwa data yang digunakan dalam penelitian ini terdapat dua variabel, yaitu kompetensi dan kinerja dengan jumlah sampel sebanyak 25 . Untuk variabel kompetensi memiliki nilai minimum 23, maksimum 55, mean 37,64 dan standar deviation sebesar 7.376. Sedangkan untuk variabel kinerja memiliki nilai minimum 29, maksimum 40, mean 34,44 dan standar deviation sebesar 3.895.

\section{Uji Kualitas Data}

Uji ini dilakukan untuk mengetahui apakah item-item pertanyaan pada kuisioner sudah layak digunakan atau belum. Uji ini penting dilakukan karena memiliki pengaruh atas kualitas dari hasil penelitian ini. Uji ini terdiri dari 2 pengujian yaitu uji validitas dan uji reliabilitas. Sesuai dengan yang dikatakan oleh Sugiyono (2019: 31) insturmen dapat dipercaya setelah memenuhi pengujian validitas dan uji reliabilitas. Hasil pengujian validitas akan dilampirkan dibawah ini :

\section{Tabel 3. Uji Validitas Kompetensi}

\begin{tabular}{l|r|r|}
\multicolumn{2}{l}{ Correlations } \\
Pearson Correlation & R hitung & R tabel \\
\hline $\mathrm{X} 1$ & 0,608 & 0,396 \\
\hline $\mathrm{X} 2$ & 0,615 & 0,396 \\
\hline $\mathrm{X} 3$ & 0,808 & 0,396 \\
\hline $\mathrm{X} 4$ & 0,752 & 0,396 \\
\hline $\mathrm{X} 5$ & 0,573 & 0,396 \\
\hline $\mathrm{X} 6$ & 0,638 & 0,396 \\
\hline $\mathrm{X} 7$ & 0,575 & 0,396 \\
\hline $\mathrm{X} 8$ & 0,664 & 0,396 \\
\hline $\mathrm{X} 9$ & 0,584 & 0,396 \\
\hline $\mathrm{X} 10$ & 0,682 & 0,396 \\
\hline $\mathrm{X} 11$ & 0,662 & 0,396 \\
\hline Sumber : SPSS.26, diolah penulis $(2021)$
\end{tabular}

$\begin{gathered}\text { Tabel 4. Uji Validitas Kinerja } \\
\text { Correlations }\end{gathered}$
\begin{tabular}{c|r|r} 
& \\
Pearson Correlation & R hitung & R tabel \\
\hline Y1 & 0,720 & 0,396 \\
\hline Y2 & 0,806 & 0,396 \\
\hline Y3 & 0,805 & 0,396 \\
\hline Y4 & 0,550 & 0,396 \\
\hline Y5 & 0,662 & 0,396 \\
\hline Y6 & 0,547 & 0,396 \\
\hline Y7 & 0,576 & 0,396 \\
\hline Y8 & 0,553 & 0,396 \\
\hline Sumber : SPSS.26, diolah penulis $(2021)$
\end{tabular}

Berdasarkan hasil uji validitas dapat diinterpretasikan bahwa seluruh item-item yang digunakan pada kuisioner ini valid karena nilai $\mathrm{R}$ hitung lebih besar dari $\mathrm{R}$ tabel. Maka selanjutnya akan dilakukan uji reliabilitas, berikut hasilnya:

\section{Tabel 5. Uji Reliabilitas Kompetensi Reliability Statistics}

Sumber : $\frac{\frac{\text { Cronbach's Alpha N of Items }}{.864} 11}{\text { SPS.26, diolah penulis (2021) }}$

Tabel 6. Uji Reliabilitas Kinerja

Reliability Statistics

\begin{tabular}{r|r}
$\frac{\text { Cronbach's Alpha }}{2}$ & N of Items \\
\cline { 2 - 3 } Sumber $:$ SPSS.26, diolah penulis (2021)
\end{tabular}

Berdasarkan hasil uji reliabilitas dapat diinterpretasikan bahwa seluruh item-item yang digunakan pada kuisioner ini reliable karena lebih besar dari 0,60. Maka selanjutnya akan dilakukan uji asumsi klasik, berikut hasilnya :

Uji Asumsi Klasik Normalitas

Tabel 7. Uji Normalitas

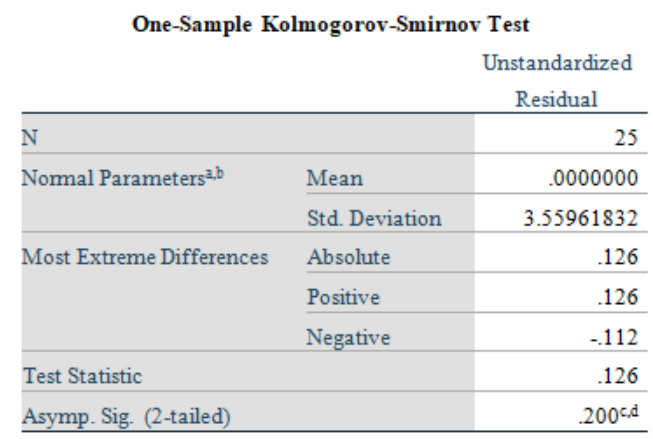

a. Test distribution is Normal.

b. Calculated from data.

c. Lilliefors Significance Correction.

d. This is a lower bound of the true significance.

\section{Sumber : SPSS.26, diolah penulis (2021)}

Berdasarkan hasil pengolahan uji normalitas menggunakan one sample Kolmogorov smirnov test, didapatkan nilai signifikansi sebesai 0,200 yang mana nilai ini lebih besar dari 0,05 maka dapat 
Multikolinieritas

Tabel 8. Uji Multikolinieritas

\section{Coefficients $^{\mathrm{a}}$}

\begin{tabular}{|c|c|c|c|c|c|c|c|c|}
\hline \multirow[b]{2}{*}{ Model } & & \multicolumn{2}{|c|}{ Unstandardized Coefficients } & \multirow{2}{*}{$\begin{array}{c}\text { Standardized } \\
\text { Coefficients } \\
\text { Beta }\end{array}$} & \multirow[b]{2}{*}{$\mathrm{t}$} & \multirow[b]{2}{*}{ Sig. } & \multicolumn{2}{|c|}{ Collinearity Statistics } \\
\hline & & $\mathrm{B}$ & Std. Error & & & & Tolerance & VIF \\
\hline \multirow[t]{2}{*}{$\overline{1}$} & (Constant) & 42.512 & 3.857 & & 11.023 & .000 & & \\
\hline & kompetensi & -.214 & .101 & -.406 & -2.131 & .044 & 1.000 & 1.000 \\
\hline
\end{tabular}

a. Dependent Variable: kinerja

Sumber : SPSS.26, diolah penulis (2021)

Berdasarkan hasil pengujian multikolinieritas didapatkan nilai VIF sebesar 1 yang mana nilai tersebut kurang dari 10 maka dapat diinterpretasikan bahwa data yang digunakan tidak terjadi multikolinieritas

Heterokedastisitas (uji glejser)

\section{Tabel 9. Uji Heterokedastisitas}

\begin{tabular}{|c|c|c|c|c|c|c|}
\hline \multicolumn{7}{|c|}{ Coefficients $^{\mathrm{a}}$} \\
\hline & & \multicolumn{2}{|c|}{ Unstandardized Coefficients } & \multirow{2}{*}{$\begin{array}{c}\text { Standardized } \\
\text { Coefficients } \\
\text { Beta }\end{array}$} & \multirow[b]{2}{*}{$\mathrm{t}$} & \multirow[b]{2}{*}{ Sig. } \\
\hline & & $\mathrm{B}$ & Std. Error & & & \\
\hline \multirow[t]{2}{*}{1} & (Constant) & .702 & 1.590 & & .442 & .663 \\
\hline & kompetensi & .065 & .041 & .310 & 1.563 & .132 \\
\hline
\end{tabular}

a. Dependent Variable: RES2

Sumber : SPSS.26, diolah penulis (2021)

Dari hasil uji tersebut dihasilkan nilai signifikansi sebesar 0,132 yang mana nilai ini lebih dari 0,05 yang dapat diinterpretasikan bahwa dalam data ini tidak terjadi masalah heterokedastisitas.

Uji Autokorelasi

\section{Tabel 10. Uji Autokorelasi}

\section{Model Summary}

\begin{tabular}{|c|c|c|c|c|c|}
\hline Model & $\mathrm{R}$ & R Square & $\begin{array}{l}\text { Adjusted R } \\
\text { Square }\end{array}$ & $\begin{array}{l}\text { Std. Error of the } \\
\text { Estimate }\end{array}$ & Durbin-Watson \\
\hline 1 & $.406^{\mathrm{a}}$ & .165 & .129 & 3.636 & 2.022 \\
\hline
\end{tabular}

a. Predictors: (Constant), kompetensi

b. Dependent Variable: kinerja 
Berdasarkan hasil table uji autokorelasi didapatkan nilai durbin Watson sebesar 2.022, dan diketahui dalam penelitian ini menggunakan 25 sampel dan 1 variabel bebas mana didapatkan nilai $\mathrm{dL}=1.2879$ dan nilai $\mathrm{dU}=1.4614$
Karena dU $(1.4614)<\mathrm{dw}(2.022)<4-\mathrm{dU}(2,5386)$ maka dapat diinterpretasikan pada data ini tidak terjadi autokorelasi

Regresi Linier Sederhana

Tabel 11. Uji Regresi Linier Sederhana

\begin{tabular}{|c|c|c|c|c|c|c|}
\hline \multicolumn{7}{|c|}{ Coefficients $^{\mathrm{a}}$} \\
\hline & & \multicolumn{2}{|c|}{ Unstandardized Coefficients } & $\begin{array}{l}\text { Standardized } \\
\text { Coefficients }\end{array}$ & & \\
\hline \multicolumn{2}{|c|}{ Model } & B & Std. Error & Beta & $\mathrm{t}$ & Sig. \\
\hline \multirow[t]{2}{*}{1} & (Constant) & 42.512 & 3.857 & & 11.023 & .000 \\
\hline & kompetensi & -.214 & .101 & -.406 & -2.131 & .044 \\
\hline
\end{tabular}

a. Dependent Variable: kinerja

Sumber : SPSS.26, diolah penulis (2021)

Berdasarkan pengujian regresi linier sederhana maka

$\operatorname{Kinerja}(\mathrm{Y})=42.512-0.214 \mathrm{X}+\mathrm{e} \quad \rightarrow(1)$ dalam penelitian ini diperoleh hasil persamaan sebagai berikut

Koefisien Determinasi $\left(\mathrm{R}^{2}\right)$

Tabel 12. Uji Koefisien Determinasi

Model Summary ${ }^{b}$

\begin{tabular}{|c|c|c|c|c|c|}
\hline Model & $\mathrm{R}$ & R Square & $\begin{array}{l}\text { Adjusted R } \\
\text { Square }\end{array}$ & $\begin{array}{l}\text { Std. Error of the } \\
\text { Estimate }\end{array}$ & Durbin-Watson \\
\hline & $.406^{\mathrm{a}}$ & .165 & .129 & 3.636 & 2.022 \\
\hline
\end{tabular}

a. Predictors: (Constant), kompetensi

b. Dependent Variable: kinerja

Sumber : SPSS.26, diolah penulis (2021)

Berdasarkan hasil pengujian koefisien determinasi dalam penelitian ini didapatkan sebesar 0,165 atau $16,5 \%$ menunjukkan bahwa variabel kompetensi berpengaruh sebesar $16,5 \%$ terhadap kinerja. Untuk sisanya sebesar $83,5 \%$ dipengaruhi oleh variabel lain yang tidak diteliti dalam penelitian ini.

Uji T

Tabel 13. Uji T

Coefficients $^{\mathrm{a}}$

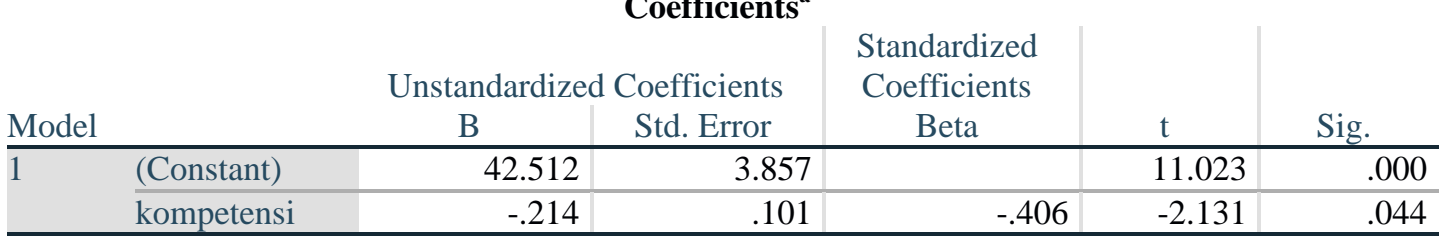

a. Dependent Variable: kinerja

Sumber : SPSS.26, diolah penulis (2021) 
Berdasarkan hasil pengujian tersebut, didapatkan nilai signifikan sebesar 0,044 yang mana nilai tersebut kurang dari 0,05 yang mana dapat diinterpretasikan bahwa variabel kompetensi berpengaruh terhadap komptensi. Maka dalam penelitian ini dapat dinyatakan bahwa $\mathrm{H}_{1}$ diterima.

\section{SIMPULAN}

Hasil penelitian ini dapat disimpulkan Kompetensi Berpengaruh Terhadap Kinerja dan Koefisien Determinasi yang dijelaskan oleh variabel kompetensi terhadap kinerja sebesar sebesar 16,5\% untuk mempengaruhi kinerja, sedangkan sisanya sebesar $83,5 \%$ dipengaruhi oleh variabel lain yang tidak diteliti dalam penelitian ini.

\section{DAFTAR PUSTAKA}

Gomes, Faustino Cardoso, 2003, Manajemen Sumber Daya Manusia. Yogyakarta: Andi Offset.

Mangkunegara, Anwar Prabu. 2006. Evaluasi Kinerja SDM. Bandung: Refika Aditama.

Mangkunegara, Anwar Prabu. 2006. Manajemen Sumber Daya Manusia Perusahaan. Bandung: Rosda.

Mangkunegara, A.A Anwar Prabu, 2002. Manajemen $S$ umber Daya Manusia.Bandung: Remaja Rosda Karya.

Noe, Hollenbeck, Gerhart Wrigth, (2006), Human Resources Management, Gaining A Competitive Advantage, McGraw - Hill.

Noe, Hollenbeck, Gerhart Wright, (1997), Human Resource Management, Gaining to Competitive Advantage, International Edition, McGraw-Hill, Inc., USA.

Robert L. Mathis, John H. Jackson, (2004), Human Resources Management $10^{\text {th }}$.

Rifai, R. A. (2009). Pengantar Manajemen. Fakultas Ekonomi dan Bisnis Universitas Muhammadiyah Palembang.

Simanjuntak,Payaman J, Prof.Dr, 2005, Manajemen dan Evaluasi Kinerja, Fakultas Ekonomi Universitas Indonesia.

Siagian, Sondang P. 2001 Kiat Meningkatkan Produktivitas Kerja. Jakarta. Rineka Cipta.

Sugiyono. (2019). Metode Penelitian Kuantitatif Kualitatif dan $R \& D$. Alfabeta cv.
Sukmalana, Soelaiman. 2009. Manajemen Kinerja Membangun, Mengembangkan Kinerja Sumber Daya Manusia dan Organisasi/Bisnis. Jakarta: PT. Intermedia Personalia Utama.

Umar, Husen. 2004. Riset Sumber Daya Manusia. Jakarta: Gramedia Pustaka Utama.

Wibowo. (2014). Manajemen Kinerja. PT Raja Grafindo Persada. 